\title{
ANALISA PARKIR PARAGON MALL SEMARANG
}

\author{
Mudjiastuti Handajani $^{1}$, Tut Wuri Handayani ${ }^{2}$ \\ 1) Jurusan Teknik Sipil Universitas Semarang \\ Jl. Soekarno Hatta, Tlogosari, Semarang, telp: 081390959909, email:hmudjiastuti@yahoo.co.id \\ 2) Jurusan Teknik Sipil Universitas Semarang \\ Jl. Soekarno Hatta, Tlogosari, Semarang, telp: 085640938171, email: cemutdhandayani@yahoo.co.id
}

\begin{abstract}
Pull traffic that occurs in complex Paragon Mall affect parking demand in these locations. For that we need research to obtain data - data that is requirsed by way of observations of drivers and parking attendants. The intent and purpose of this paper is to get the amount of traffic traveling tug toward Paragon Mall shopping complex and to determine parking demand at Paragon Mall shopping complex. Furthermore, based on the data that has been obtained so that data processing is done to obtain the desired result of which the accumulated maximum parking, towing trips, towing traffic, parking demand factors. From the calculation it is known that the maximum accumulation occurs on a Saturday, which is 173 to 295 types of automobiles and vehicle type motorcycle. Pull the whole trip occurred on Sunday at 4.76 people / 100m2 Floor Area Groos. The amount of traffic tug Day on Saturday by $219 \mathrm{smp} /$ hour for this type of car and $108 \mathrm{smp} /$ hour for this type of motorcycle. Thus Paragon Mall has considerable pull the trip and have enough parking area where the number of plots for the car park as many as 260 plots for motorcycle parking and 800 parking plots.
\end{abstract}

Keywords: Parking, Paragon Mall, parking needs, parking characteristics

\begin{abstract}
Abstrak:Tarikan lalu lintas yang terjadi pada kompleks Paragon Mall mempengaruhi kebutuhan parkir di lokasi tersebut. Untuk itu diperlukan penelitian untuk mendapatkan data - data yang diperlukan yaitu dengan cara pengamatan pengemudi dan petugas parkir. Tujuan dari penelitian ini adalah untuk mendapatkan besarnya tarikan perjalanan lalu lintas yang menuju kompleks pertokoan Paragon Mall dan untuk mengetahui faktor kebutuhan parkir pada kompleks pertokoan Paragon Mall. Berdasarkan data yang telah didapatkan maka dilakukan pengolahan data tersebut untuk mendapatkan hasil yang diinginkan diantaranya akumulasi parkir maksimum, tarikan perjalanan, tarikan lalu lintas, faktor kebutuhan parkir. Dari hasil perhitungan diketahui bahwa akumulasi maksimum terjadi pada hari Sabtu, yaitu 173 untuk jenis kendaraan mobil dan 295 untuk jenis kendaraan sepeda motor. Tarikan perjalanan orang keseluruhan terbanyak terjadi pada hari Minggu sebesar 4,76 orang/100 ${ }^{2}$ Groos Floor Area. Besarnya tarikan lalu lintas Harian pada Sabtu sebesar $219 \mathrm{smp} / \mathrm{jam}$ untuk jenis mobil dan $108 \mathrm{smp} / \mathrm{jam}$ untuk jenis sepeda motor. Dengan demikian Paragon Mall memiliki tarikan perjalanan orang yang cukup dan memiliki lahan parkir yang cukup dimana jumlah petak parkir untuk mobil sebanyak 260 petak parkir dan untuk sepeda motor sebanyak 800 petak parkir.
\end{abstract}

Kata kunci: Parkir, Paragon Mall, Kebutuhan Parkir, Karakteristik Parkir

\section{PENDAHULUAN}

Keberhasilan pembangunan di
Indonesia di tandai dengan peningkatan
pertumbuhan ekonomi yang berarti juga
peningkatan standar kehidupan masyarakat.
Hal ini dapat dilihat dari munculnya pusat -
pusat kegiatan, yang berarti menambah
intensitas pergerakan barang dan orang, baik
dari rumah ke pusat kegiatan ataupun
sebaliknya. Konsekuensi yang timbul dari

pertumbuhan ekonomi adalah meningkatnya permintaan terhadap pembangunan fisik baik prasarana maupun sarana akibat meningkatnya aktivitas manusia. Konsep transportasi berkelanjutan menjadi penting dalam hal perkembangan atau pertumbuhan transportasi yang berkelanjutan (Mudjiastuti, 2011). Pembangunan Kota Semarang mengalami laju pertumbuhan yang cukup pesat. Laju pertumbuhan Kota Semarang yang 
memungkinkan adanya jarak antara tempat tinggal dengan pusat kegiatan, menyebabkan semakin meningkatnya pemilik maupun pengguna kendaraan. Namun ternyata, pertumbuhan pemilik ataupun pengguna kendaraan tidak seimbang dengan pertumbuhan prasarana dan fasilitas yang ada. Pembangunan pusat perbelanjaan maupun kompleks pertokoan menyebabkan pemilik ataupun pengguna kendaraan untuk dating ketempat tersebut. Pertumbuhan gedung pusat perbelanjaan dan pertokoan turut meningkatkan tarikan pergerakan penduduk sehingga menambah volume parker kendaraan di areal parkir. Sebenarnya pertambahan volume kendaraan berhubungan langsung dengan luas lantai terisi gedung pusat belanja, dan laju tarikan kendaraan. Dampak yang disebabkan oleh gedung pusat perbelanjaan berupa penambahan jumlah kendaraan di areal parkir. Dampak ini dipengaruhi oleh tarikan lalu lintas gedung pusat perbelanjaan dan kapasitas parkirnya. Perubahan dampak ini dapat dijadikan pertimbangan terhadap standar pembangunan gedung pusat perbelanjaan yang lainnya seperti luas areal dan standar petak parkir yang disediakan.

Khusus untuk Kota Semarang, keberadaaan kawasan pertokoan di Paragon Mall dapat menimbulkan tarikan perjalanan kendaraan dan manusia menuju kawasan tersebut. Kawasan pertokoan Paragon Mall di kelilingi berbagai toko - toko yang mempengaruhi tarikan orang dan kendaraan. Jumlah pegawai yang bekerja di Paragon Mall menyebabkan pergerakan kendaraan pada pagi hari sangat padat di sekitar kawasan Paragon Mall. Sebagai pusat kegiatan bisnis harus menyediakan fasilitas parkir di dalam gedung sehingga fasilitas parker harus memenuhi jumlah kendaraan yang masuk ke kawasan tersebut. Aktivitas sehari-hari yang terjadi di kompleks pertokoan yang menyediakan berbagai kebutuhan konsumen yang belum terpenuhi menyebabkan tarikan manusia dan kendaraan yang cenderung mempengaruhi kelancaran lalu lintas pada waktu puncak. Besarnya tarikan yang terjadi khususnya kendaraan, menyebabkan pihak pengelola gedung harus menyediakan lahan parkir yang memadai dengan sistem operasi yang sesuai dengan keadaan di areal parkir.

Fasilitas parkir yang ada harus memberikan keamanan dan kenyamanan bagi kendaraan. Fasilitas parker harus dapat mengurangi kemungkinan terjadinya tundaan dan konflik. Elemen-elemen perancangan yang harus dipertimbangkan meliputi penentuan dimensi petak parkir, lebar jalan masuk maupun keluar, dan aksesibilitas terhadap jalan raya sekitarnya (Wardhana, 2005). Luas areal parker harus disesuaikan dengan banyaknya kendaraan yang masuk dan keluar, sehingga bias memungkinkan pihak pengelola gedung mengadakan perluasan areal parkir, hal ini bias terjadi apabila tarikan kendaraan yang terjadi setiap hari cukup besar.

\section{TINJAUAN PUSTAKA}

\section{Karakteristik Arus Lalu Lintas}

Karakteristik volume lalu lintas didefinisikan sebagai variasi volume lalu lintas menurut waktu dan menurut arah. Variasi menurut waktu berarti variasi volume lalu lintas tersebut sejalan dengan perubahan waktu di dalam periodanya. Variasi menurut arah berarti 
variasi volume yng disebabkan perubahan arah lalu lintas yang lebih dominan. Menurut (Chisty, 2006) karakteristik arus lalu lintas dibedakan menjadi:

1. Headway adalah ukuran interval waktu kedatangan antara kendaraan (diukur pada titik bagian depan kendaraan, misal: bumper) yang melintasi titik tertentu.

2. Kecepatan rata - rata adalah ukuran yang penting dari kinerja lalu-lintas, yangdinyatakan dalam kilometer/jam atau mil/jam. Terdapat dua jenis kecepatan rata-rata, yakni: kecepatan sesaat ratarata (spot speed) atau time mean speed, dan kecepatan rata-rata ruang (space mean speed) atau travel time.

3. Kecepatan sesaat rata-rata (spot speed)yaitu nilai rata-rata dari serangkaian kecepatan sesaat dari individu kendaraan yang melintasi titik tertentu pada suatu ruas jalan.

\section{J enis Parkir}

Parkir adalah menghentikan kendaraan bermotor beberapa saat lamanya. Parkir meninggalkan kendaraan di pinggir jalan atau di suatu areal dengan keadaan kendaraan mati. Standing suatu kejadian dimana kendaraan berhenti sesaat lamanya dengan mesin hidup. Berhenti (stopping) adalah suatu keadaan kendaraan berhenti sesaat di pinggir jalan untuk menaik-turunkan penumpang ataupun barang.

Dalam bukunya (Tamin, 2006) secara umum jenis parkir dapat diklasifikasikan atas 2 (dua) jenis, yaitu :

1. Parkir di Badan Jalan (On-street Parking). Parkir di jalan sudah pasti mengurangi kapasitas ruas jalan yang bersangkutan, dan karena itu tidak dapat dibiarkan begitu saja. Jenis parkir ini sangat merugikan bagi pemakai jalan bila tidak diatur dengan baik.

2. Parkir di Luar Badan Jalan (Off-street Parking).

Perparkiran yang ideal adalah di luar jalan berupa fasilitas pelataran parkir atau bangunan parkir. Di pusat kegiatan kota yang sulit memperoleh lahan yang cukup luas, fasilitas yang sesuai adalah gedung parkir yang dapat dibangun bertingkat sesuai kebutuhan.

Permukaan yang dibutuhkan untuk parkir dalam berbagai kedudukan sudut parkir dapat dilihat dalam tabel di bawah ini: 
Tabel 1. Permukaan Parkir Dalam Berbagai Kemiringan Sudut

\begin{tabular}{|c|c|c|c|c|c|c|c|c|c|}
\hline \multicolumn{6}{|c|}{ Kriteria Parkir } & \multicolumn{2}{|c|}{ Satu Lajur } & \multicolumn{2}{|c|}{ Dua Lajur } \\
\hline $\begin{array}{c}\text { Sudut } \\
\text { Parkir } \\
\left(n^{0}\right)\end{array}$ & $\begin{array}{c}\text { Lebar } \\
\text { Ruang } \\
\text { Parkir } \\
\text { (A) } \\
\text { (m) }\end{array}$ & $\begin{array}{c}\text { Ruang } \\
\text { Parkir } \\
\text { Efektif } \\
\text { (D) } \\
\text { (m) }\end{array}$ & $\begin{array}{l}\text { Ruang } \\
\text { Manuver } \\
\text { (M) } \\
\text { (m) }\end{array}$ & $\begin{array}{c}D+M \\
(E) \\
(m)\end{array}$ & $\begin{array}{c}\mathrm{D}+\mathrm{J} \\
(\mathrm{m})\end{array}$ & $\begin{array}{c}\text { Lebar } \\
\text { Jalan } \\
\text { Efektif } \\
(\mathrm{L}) \\
(\mathrm{m}) \\
\end{array}$ & $\begin{array}{c}\text { Lebar } \\
\text { Total } \\
\text { Jalan } \\
(\mathrm{W}) \\
(\mathrm{m})\end{array}$ & $\begin{array}{c}\text { Lebar } \\
\text { Jalan } \\
\text { Efektif } \\
(\mathrm{L}) \\
(\mathrm{m})\end{array}$ & $\begin{array}{c}\text { Lebar } \\
\text { Total } \\
\text { Jalan } \\
(\mathrm{W}) \\
(\mathrm{m})\end{array}$ \\
\hline 0 & 2,3 & 2,3 & 3,0 & 5,3 & 2,8 & 3,5 & 6,3 & 7,0 & 9,8 \\
\hline 30 & 2,5 & 4,5 & 2,9 & 7,4 & 4,9 & 3,5 & 8,4 & 7,0 & 11,9 \\
\hline 45 & 2,5 & 5,1 & 3,7 & 8,8 & 6,3 & 3,5 & 9,8 & 7,0 & 13,3 \\
\hline 60 & 2,5 & 5,3 & 4,6 & 9,9 & 7,4 & 3,5 & 10,9 & 7,0 & 14,4 \\
\hline 90 & 2,5 & 5,0 & 5,8 & 10,8 & 10,8 & 3,5 & 11,8 & 7,0 & 15,3 \\
\hline
\end{tabular}

Sumber: Tamin, 2006

\section{Karakteristik Parkir}

1. Durasi Parkir

Informasi ini dapat diperoleh dengan cara

mengamati waktu kendaraan masuk dan

waktu kendaraan tersebut keluar, selisih

dari waktu tersebut adalah durasi parkir.

2. Akumulasi Parkir

Informasi ini dapat diperoleh dengan

menjumlahkan kendaraan yang telah

menggunakan lahan parkir ditambah

dengan kendaraan yang masuk serta

dikurangi kendaraan yang keluar.

3. Turn Over

Informasi ini dapat diperoleh dari jumlah

kendaraan yang memanfaatkan lahan

parkir pada selang waktu tertentu dibagi

dengan ruang parkir tersedia.

4. Volume Parkir

Jumlah kendaraan yang telah

menggunakan ruang parkir pada suatu

lahan parkir tertentu dalam satu satuan

waktu.
5. Kapasitas Parkir

Banyaknya kendaraan yang dapat

dilayani oleh suatu lahan parkir selama

waktu pelayanan.

6. Indeks Parkir

Merupakan persentase dari akumulasi jumlah kendaraan pada selang waktu tertentu dibagi dengan ruang parkir yang tersedia dikalikan $100 \%$.

\section{HASIL DAN PEMBAHASAN}

\section{Tingkat Perjalanan}

Tingkat perjalanan orang keseluruhan diambil dari hasil pengamatan para pengunjung yang datang menggunakan kendaraan pribadi baik mobil atau sepeda motor dan para para pejalan kaki atau yang menggunakan angkutan umum.

Dari data survei perjalanan seperti yang ditunjukkan Tabel 2, maka diperoleh tingkat perjalanan orang keseluruhan untuk ketiga hari survei adalah sebagai berikut : 
Tabel 2. Tingkat Perjalanan Orang Keseluruhan per Hari

\begin{tabular}{l|c}
\hline & Pengunjung yang Masuk \\
\hline $\begin{array}{l}\text { Selasa, 15 Maret 2016 } \\
\text { Jumlah Pengunjung }\end{array}$ & 2026 \\
\hline $\begin{array}{l}\text { Tingkat Perjalanan } \\
\left(\text { Orang/100 } \mathrm{m}^{2} \mathrm{GFA}\right)\end{array}$ & 7,67 \\
\hline $\begin{array}{l}\text { Sabtu, 19 Maret 2016 } \\
\text { Jumlah Pengunjung }\end{array}$ & 2271 \\
\hline $\begin{array}{l}\text { Tingkat Perjalanan } \\
\left(\text { Orang/100 m }{ }^{2} \text { GFA) }\right.\end{array}$ & 8,60 \\
\hline $\begin{array}{l}\text { Minggu, } 20 \text { Maret 2016 } \\
\text { Jumlah Pengunjung }\end{array}$ & 2361 \\
\hline $\begin{array}{l}\text { Tingkat Perjalanan } \\
\left(\text { Orang/100 } \mathrm{m}^{2} \mathrm{GFA}\right)\end{array}$ & 8,89 \\
\hline
\end{tabular}

Sumber: Hasil Analisa, 2016

Tingkat perjalanan untuk masing masing kendaraan yang dapat dilihat dalam Tabel 3 di bawah ini :

Tabel 3. Tingkat Perjalanan Kendaraan Masuk per Hari

\begin{tabular}{|c|c|c|}
\hline & Mobil & Sepeda Motor \\
\hline $\begin{array}{l}\text { Selasa, } 15 \text { Maret } 2016 \\
\text { Jumlah Kendaraan }\end{array}$ & 153 & 407 \\
\hline $\begin{array}{l}\text { Tingkat Perjalanan } \\
\text { (Kend/100 } \mathrm{m}^{2} \text { GFA) }\end{array}$ & 0,58 & 1,54 \\
\hline $\begin{array}{l}\text { Sabtu, } 19 \text { Maret } 2016 \\
\text { Jumlah Kendaraan }\end{array}$ & 219 & 504 \\
\hline $\begin{array}{l}\text { Tingkat Perjalanan } \\
\left(\text { Kend } / 100 \mathrm{~m}^{2} \mathrm{GFA}\right)\end{array}$ & 0,82 & 1,90 \\
\hline $\begin{array}{l}\text { Minggu, } 20 \text { Maret } 2016 \\
\text { Jumlah Kendaraan }\end{array}$ & 185 & 449 \\
\hline $\begin{array}{l}\text { Tingkat Perjalanan } \\
\left(\text { Kend } / 100 \mathrm{~m}^{2} \text { GFA }\right)\end{array}$ & 0,70 & 1,70 \\
\hline
\end{tabular}

Berdasarkan Tabel 3 tingkat perjalanan kendaraan masuk per hari di kawasan Paragon Mall dapat dilihat tarikan perjalanan maksimum terjadi pada hari Sabtu sebesar 219 mobil dengan total tingkat perjalanan sebesar $0,82 \mathrm{kend} / 100 \mathrm{~m}^{2}$ GFA dan 504 sepeda motor dengan total tingkat perjalanan sebesar 1,90 kend/100 $\mathrm{m}^{2}$ GFA. Tingkat perjalanan orang tanpa menggunakan kendaraan untuk ketiga hari survei adalah sebagai berikut : 
Tabel 4. Tingkat Perjalanan Orang Tanpa Kendaraan per Hari

\begin{tabular}{l|c}
\hline & Orang yang Masuk \\
\hline $\begin{array}{l}\text { Selasa, 15 Maret 2016 } \\
\text { Jumlah Pengunjung }\end{array}$ & 1113 \\
\hline $\begin{array}{l}\text { Tingkat Perjalanan } \\
\left(\text { Orang } / 100 \mathrm{~m}^{2} \text { GFA) }\right.\end{array}$ & 4,21 \\
\hline $\begin{array}{l}\text { Sabtu, } 19 \text { Maret 2016 } \\
\text { Jumlah Pengunjung }\end{array}$ & 1120 \\
\hline $\begin{array}{l}\text { Tingkat Perjalanan } \\
\text { (Orang/100 } \mathrm{m}^{2} \text { GFA) }\end{array}$ & 4,62 \\
\hline $\begin{array}{l}\text { Minggu, } 20 \text { Maret 2016 } \\
\text { Jumlah Pengunjung }\end{array}$ & 1259 \\
\hline $\begin{array}{l}\text { Tingkat Perjalanan } \\
\left(\text { Orang } / 100 \mathrm{~m}^{2} \text { GFA) }\right.\end{array}$ & 4,76 \\
\hline
\end{tabular}

Sumber: Hasil Analisa,2016

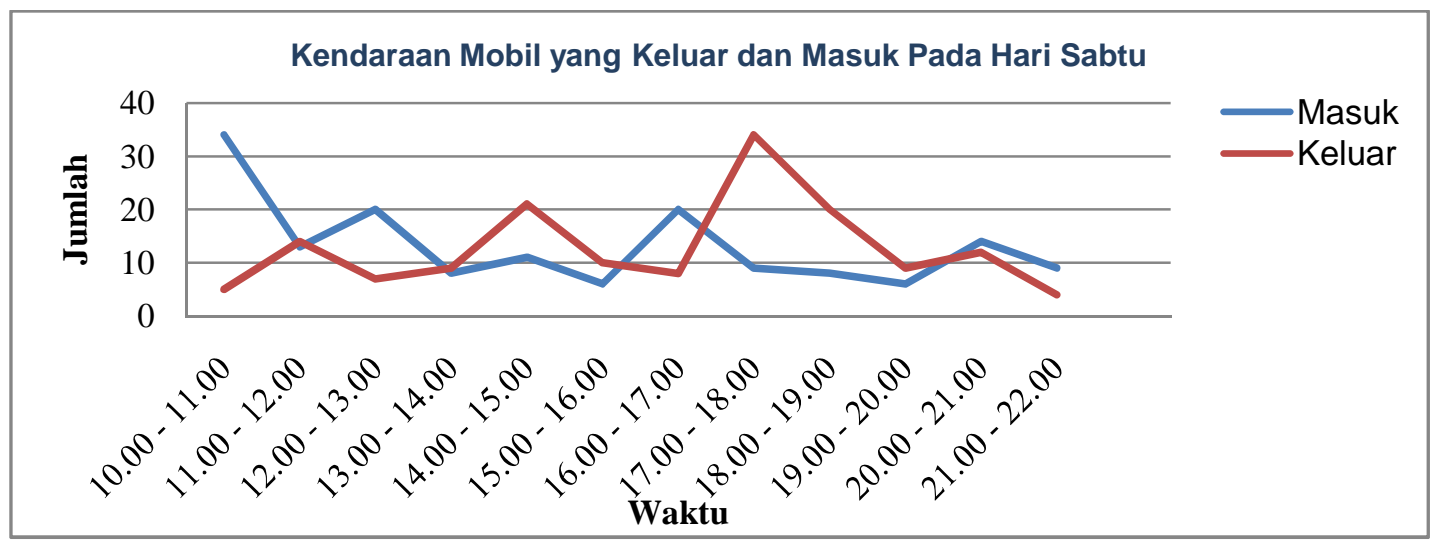

Sumber: Hasil Analisa, 2016

Gambar 1. Kendaraan Mobil yang Keluar dan Masuk Pada Hari Sabtu

Berdasarkan Tabel 4 tingkat perjalanan orang tanpa kendaraan di kawasan Paragon Mall dapat dilihat tarikan perjalanan maksimum terjadi pada hari Minggu sebesar 1259 pengunjung dengan total tingkat perjalanan sebesar 4,76 orang/100 m² GFA.

\section{Akumulasi Parkir}

Akumulasi parkir merupakan jumlah kendaraan yang parkir disuatu area pada waktu tertentu. Waktu puncak parkir dan jumlah kendaraan parkir dapat diperoleh dari hasil akumulasi parkir. Data yang diperoleh selama tiga hari dilakukan pencatatan jumlah kendaraan yang masuk dan keluar kemudian dikelompokkan dalam interval waktu 15 menit-an, sehingga didapatkan persentase distribusi kendaraan keluar masuk dan angka akumulasi parkir.

Berdasarkan Gambar 1 dapat dilihat puncak pergerakan mobil keluar dari Paragon Mall terjadi pada pukul 17.00 - 18.00, hal ini disebabkan karena pada jam itu akan menjelang di laksanakan ibadah solat maghrib sehingga para jama'ah yang ingin beribadah sementara meninggalkan pusat perbelanjaan tersebut. Pada pukul 10.00 - 11.00 sudah 
banyak mobil yang memasuki kawasan parkiran Paragon Mall, karena pada jam tersebut merupakan jam dimana para karyawan memulai beraktivitas.Pada pukul 16.00 - 17.00 banyak mobil yang memasuki kawasan parkiran Paragon Mall, karena sebagian besar pengunjung menghabiskan waktu malam minggu dengan berbelanja di mall tersebut.

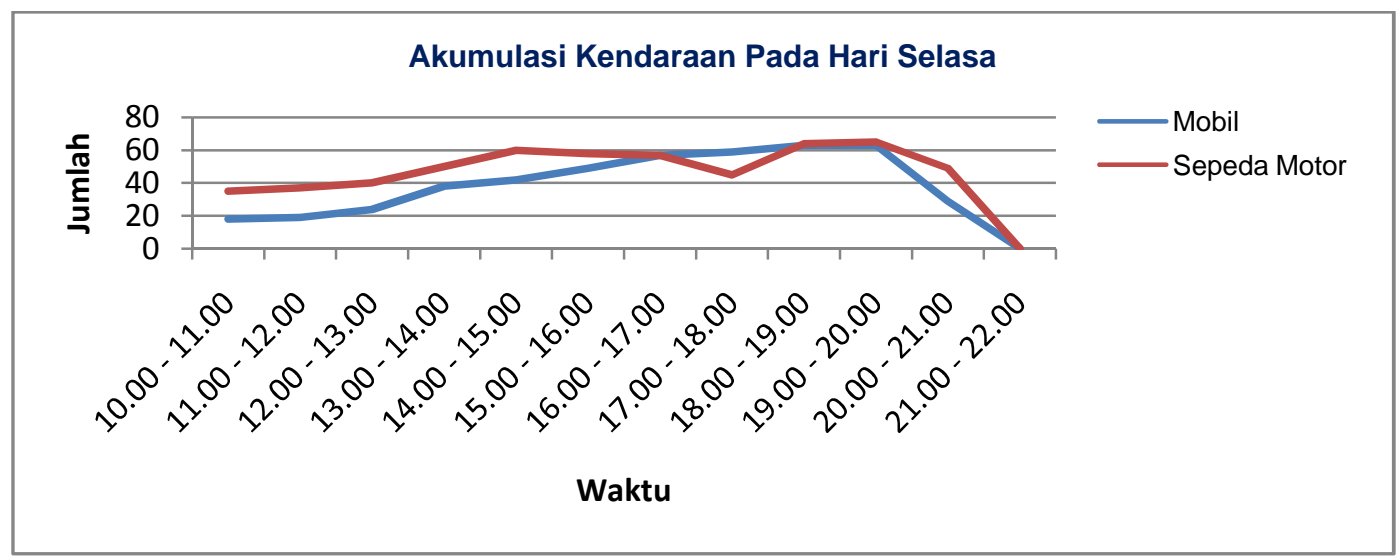

Sumber: Hasil Analisa, 2016

Gambar 2. Akumulasi Kendaraan Pada Hari Selasa

Berdasarkan Gambar 2 dapat dilihat persentase maksimum mobil masuk terjadi pada pukul 13.00 - 14.00 sebesar 15,2\% dengan mobil masuk sebanyak 18 buah, dengan total mobil masuk secara sebanyak 118 buah, sedangkan yang keluar terjadi pada pukul $20.00-21.00$ sebesar $28,8 \%$ dengan mobil yang keluar sebanyak 34 buah. Persentase maksimum sepeda motor terjadi pada pukul 18.00 - 19.00 sebanyak $17,7 \%$ dengan sepeda motor masuk sebanyak 22 buah, dengan total sepeda motor masuk secara sebanyak 124 buah, sedangkan yang keluar terjadi pada pukul 21.00 - 22.00 sebesar 39,5\% sebanyak 49 buah sepeda motor keluar, dengan total sepeda motor keluar secara sebanyak 124 buah dan akumulasi maksimum sepeda motor atau mobil terjadi pada pukul $19.00-20.00$.
Berdasarkan Gambar 2 dapat dilihat puncak pergerakan mobil yang keluar dan masuk dari Paragon Mall terjadi pada pukul 18.00 - 19.00 dan pukul 19.00 - 20.00, hal ini disebabkan karena pada jam itu sebagian besar pengunjung banyak yang ingin menonton bioskop di XXI. Pada pukul 20.00 21.00 banyak sepeda motor yang mulai meninggalkan kawasan parkiran Paragon Mall, karena pada jam tersebut sudah menjelang malam hari dan keesokan harinya orang orang harus memulai aktivitasnya kembali.Pada pukul 21.00 - 22.00 banyak mobil maupun sepeda motor yang meninggalkan kawasan parkiran Paragon Mall, karena sebagian besar outlet - outlet atau toko di dalam Paragon Mall sudah mulai tutup sehingga tidak ada aktivitas di dalam mall tersebut. 


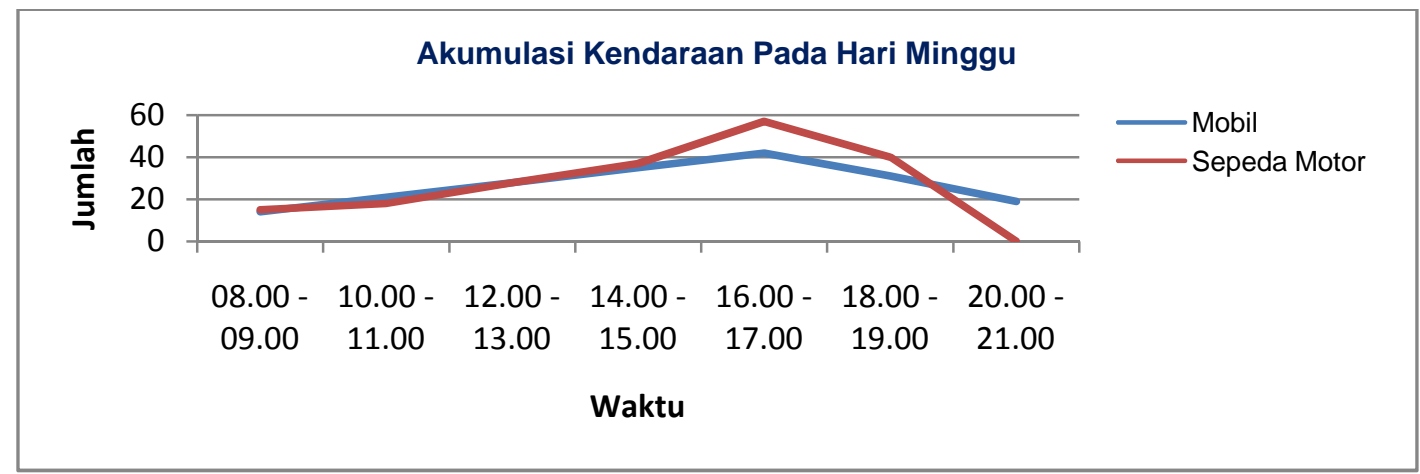

Sumber: Hasil Analisa, 2016

Gambar 3. Akumulasi Kendaraan Pada Hari Minggu

Berdasarkan Gambar 3 dapat dilihat puncak pergerakan sepeda motor yang keluar dan masuk dari Paragon Mall terjadi pada pukul 16.00 - 17.00, hal ini disebabkan karena pada jam itu sebagian besar pengunjung banyak yang ingin berbelanja dan ada program midnight sale setiap minggunya. Pada pukul 20.00 - 21.00 banyak sepeda motor ataupun mobil yang mulai meninggalkan kawasan parkiran Paragon Mall, karena pada jam tersebut sudah menjelang malam hari dan keesokan harinya orang - orang harus memulai aktivitasnya kembali.Selain itu, sebagian besar outlet - outlet atau toko di dalam Paragon Mall sudah mulai tutup sehingga tidak ada aktivitas di dalam mall tersebut.

\section{Durasi Parkir}

Durasi parkir adalah rentang waktu yang digunakan oleh suatu kendaraan untuk parkir pada suatu tempat/area parkir dalam satuan menit atau jam, tanpa berpindah pindah.Durasi kendaraan parkir diperoleh dengan cara pengamatan pada pintu - pintu masuk dan keluar kendaraan. Setiap kendaraan yang masuk ke lokasi dicatat nomor plat kendaraan untuk selang waktu lima belas menit, dengan cara yang sama dilakukan pada pintu - pintu keluar.

Tabel 5. Durasi Parkir Mobil Penumpang

\begin{tabular}{l|l|c|c|c|c}
\hline No & \multicolumn{1}{|c|}{ Hari, Tanggal } & $\begin{array}{c}\text { Waktu } \\
\text { Pengamatan }\end{array}$ & $\begin{array}{c}\text { Durasi } \\
\text { Maksimum }\end{array}$ & $\begin{array}{c}\text { Durasi } \\
\text { Minimum }\end{array}$ & $\begin{array}{c}\text { Durasi Rata- } \\
\text { Rata }\end{array}$ \\
\hline 1. & Selasa, 15 Maret 2016 & $08: 00-15: 59$ & $06: 30$ & $00: 00$ & $1: 31: 46$ \\
\hline 2. & Sabtu, 19 Maret 2016 & $08: 00-15: 59$ & $06: 30$ & $00: 00$ & $1: 58: 42$ \\
\hline 3. & Minggu, 20 Maret 2016 & $08: 00-10: 59$ & $02: 00$ & $00: 00$ & $1: 27: 49$ \\
\hline
\end{tabular}

Sumber: Hasil Analisa, 2016 
Berdasarkan Tabel 5 diatas diperoleh informasi durasi rata - rata parkir mobil maksimum terjadi pada hari Sabtu, 19 Maret 2016 yaitu sebesar 1 jam 58 menit. Tabel tersebut juga menunjukkan bahwa untuk mobil durasi maksimum terjadi pada hampir semua hari aktif dan menjelang akhir pekan yaitu sebesar 6 jam 30 menit, sedangkan durasi minimum dari tiga hari pengamatan yaitu sebesar 0 sampai 15 menit. Owner dan karyawan yang mempunyai kesibukan dari pagi hingga sore hari menyebabkan mereka cenderung untuk lebih lama berada disana.

\section{KESIMPULAN}

1. a. Tingkat perjalanan harian orang tanpa menggunakan kendaraan pada Selasa sebesar 4,21 orang/100 m² GFA, Sabtu sebesar 4,43 orang/100 $\mathrm{m}^{2}$ GFA, dan Minggu sebesar 4,76 orang/100 $\mathrm{m}^{2}$ GFA.

b. Besarnya tarikan lalu lintas harian pada Selasa sebesar 153 smp/jam untuk mobil dan $81,4 \mathrm{smp} / \mathrm{jam}$ untuk sepeda motor. Besarnya tarikan lalu lintas harian pada Sabtu sebesar $219 \mathrm{smp} / \mathrm{jam}$ untuk mobil dan 100,8 smp/jam untuk sepeda motor. Sedangkan pada Minggu sebesar 185 smp/jam untuk mobil dan $89,8 \mathrm{smp} / \mathrm{jam}$ untuk sepeda motor.

2. a. Durasi parkir rata-rata kendaraan mobil adalah 301,5 menit/mobil dan sepeda motor adalah 154,4 menit/sepeda motor.

b. Akumulasi parkir kendaraan maksimum terjadi pada akhir pekan, yaitu pada Hari Sabtu, 19 Maret 2016. Terjadi akumulasi maksimum yang jumlahnya sangat tinggi, tetapi hal itu tidak diperhitungkan karena bersifat sementara dan tidak setiap pekan terjadi. Kondisi ini disebabkan karena para pengunjung dan karyawan yang mau melakukan ibadah sholat maghrib.

\section{SARAN}

1. Sebaiknya pihak parkir menempatkan petugas parkir agar pengaturan parkir dapat terlaksana dengan baik dan keamanan kendaraan dapat lebih terjamin.

2. Letak pintu keluar sepeda motor agar diperlebar agar tidak terjadi konfik saat keluar.

3. Letak parkir mobil sebaiknya lebih teratur posisinya.

4. Diharapkan kepada pengelola parkir agar membuat jalur khusus keluar masuk pengunjung yang tidak menggunakan kendaraan.

\section{DAFTAR PUSTAKA}

Baker, F, 2001. Perencanaan dan Teknik Lalu Lintas, Terjemahan oleh: Ir. Suprapto TM, Msc. Gajah Mada University Press Yogyakarta.

Bionpion, Joseph, 2003. Operations Management. Singapore: McGrawHill.

Christy, Julian, 2006. Dasar - Dasar Rekayasa Transportasi. Jakarta Erlangga:.

Direktur Jendral Perhubungan Darat, 2000. Pedoman Teknis Penyelenggaraan Fasilitas Parkir, Departemen Perhubungan, Jakarta.

Handajani, Mudjiastuti, 2011. Analisis Gradien Kepadatan Penduduk dan Konsumsi BBM, Jurnal Teknik Sipil dan Perencanaan UNNES volume 11 nomor 2 halaman 141 - 148, Semarang.

Hobbs, F.D, 2000. Traffic and Engineering, secon edition, Terjemahan oleh 
Suprapto TM dan Waldjono, Penerbit Gajah Mada Press, Yogyakarta.

Sumayang, L, 2003. Dasar - Dasar Manajemen Produksi \& Operasi, Jakarta, Salemba Empat.

Tamin, O, 2006. Tarikan dan Bangkitan Lalu Lintas Serta Kebutuhan Parkir, Erlangga:Jakarta.

Tut Wuri, 2016. Dokumentasi Pribadi Kedudukan Parkir Paragon Mall, Semarang.

Wardhana, W, 2005. Perencanaan Transportasi dan Pemodelan Transportasi, ITB, Bandung.

Warpani, Suwardjoko, 2002. Pengolahan Lalu Lintas dan Angkutan Jalan, Bhatara Karya Husada: Bandung.

Wells, Render, 2004. Operation Management 9th ed., New Jersey, Pearson. 